Paris, which were stimulated by papers by A. Banos and G. Goubau, that no completely satisfactory answer to the problem has yet been reached. Also, in the general theoretical section of the colloquium there was extensive consideration of diffraction problems, a leading part being played by V. A. Fock, who presented a comprehensive paper dealing with the application of complex integrals to these problems.

A treatment of the scattering of high-frequency radiation by dielectric spheres was given by $\mathrm{D}$. S. Saxon and $Z$. Sekera. It would seem that, while satisfactory theories exist for scattering processes when the wave-length is short compared with the scale of the inhomogeneities of the scattoring medium, they are not valid at longer wavo-lengths.

A matter of considerable importance in propagation studies is the reflexion of radio weves at rough surfaces. Various aspects of this subject were discussed by W. S. Ament, who gave quantitative results for surfaces conforming to certain simple models; and also by $\mathrm{V}$. Twersky, who presented a generalized theory-though here again only simplified models are amenable to numerical treatment.

Current interest in long-wave transmission has been stimulated by recent theoretical work on the problem, notably that by K. G. Budden in which the space between the Earth and the ionosphere is treated as a wave-guide. It is hoped that now experimental work will help to resolve some of the difficulties in the theory which still exist. In this connexion the study of atmospheries is important, and it was interesting to hear a report in Paris by J. Aaroris that measurements have now been made down to frequencies as low as 0.5 cycles per second, to supplement those which have been made for a number of years at higher frequencies.

It is proposed that the papers presented at the colloquium shall be published in a special number of L'Onde Electrique which will appear in the spring of 1957 .

\section{PHYSIOLOGY OF THE PRE-WEANING PERIOD}

A CONFERENCE, in commemoration of E. Babák, was held by the Czechoslovak Academy of Sciences at Liblice, near Prague, during November 14-17, 1956. The subject of the conference was "Problems of the Physiology of the Pre-weaning Period in Man and other Mammals". Countries represented included the German Democratic Republic, Great Britain, Hungary, Rumania, the United States, U.S.S.R. and Yugoslavia.

A central topic was the development of thermoregulation, on which extensive resoarches are being carried out in Prague, at the Institute of Physiology of the Academy of Sciences and at the Charles University. P. Hahn, J. Křeček, J. Křečkova and J. Martínek (Prague) contributed papers on the development of thermo-regulatory mechanisms in the rat, and on adaptation to cold and warm environments in infant rats. Othor pepers in this field included those of S. A. Barnett and B. M. Manly (Glasgow) on the effects of low environmental temperatures on young mice; K. W. Cross (London) on the reaction of the human new-born to lack of oxygen ; A. Holub and others (Brno) on the development of thermorcgulation in piglets ; and A. McLaren and D. Michie
(London) on the effects of low and high temperatures on growth and variability in mice.

Other aspects of homeostasis were dealt with by J. Cort (Prague), who described work on the renal tubular excretion of acids in the human new-born; and Gertrude Falk (Washington), who discussed endocrine factors in the post-natal development of water diuresis. In addition, M. Hašek (Prague) gavo an account of his important work on the adaptation of homeotherms to foreign antigens during early ontogeny.

Another major theme wes the development of the nervous system. P. K. Anochin (Moscow) described an extensive series of researches on the relationship between functional maturation in the nervous system and the appearance of innate responses. I. A. Arshavsky (Moscow) gave a paper on the nervous system in the development of gastro-intestinal and circulatory function. K. Capek and J. Jelinek described experiments on the external stimuli requirod to establish reflex micturition in puppies. P. Jilek and others discussed the development of normal brain function. J. Lát described researches in which individual variation in food choice in rats was found to be related to metabolic differences. J. L. Malcolm (London) reported on the pattern of response of motor neurons of the spinal cord in kittens, and the relationship between anatomical and functional development. A. D. Slonim (Leningrad) described a study of innate alimentary reflexes during ontogeny.

Visits were made to research institutes and medical centres in Prague. It was provisionally decided to hold a similar conference, again in Prague, in three or four years time.

S. A. BarnetT

\section{FATIGUE IN METALS}

$I^{\mathrm{N}}$

N the hundred years since the term 'fatigue' was first introduced to define a certain type of unexplained service failure, a great deal of empirical knowledge has been accumulated, but there is still much to learn regarding the fundamentals of the processes involved. The Institution of Metallurgists has published a series of five paper's*, presented as lectures during 1955, which together summarize, possibly better than has been done before, what is known and what is not known about this obscure phenomenon.

Dr. J. Holden deals with the fundamental considerations so far as they are known in a condensed but clear manner. It has been realized for a long time that fatigue depends greatly on the nature of the surface of the part under consideration, and Mr. G. Forrest is concerned to summarize the effect of notches and surface finishes, such, for excmple, as nitriding, shot-blasting, decarburization, etc., on the resistance to fatigue, and concludes that "the only general conclusion which can be reached is that the behaviour of materials with respect to notches and surface finishes is so complicated and related to so many variables that we are still a long way from being able to estimate the strength of complicated engineering components from fatigue tests on normal laboratory specimens".

* The Fatigue of Metals : Lectures delivered at the Institution's * The Fatigue of Metals: Lectures delivered at the Institution's
Refresher Course 1955. Pp. $148+16$ tables. (London: Institution $\begin{array}{ll}\text { Refresher Course 1955. Pp. } & \text { Pp. } \\ \text { of Metallurgists, 1956.) } & 25 s .\end{array}$ 
As an example of the practical aspects of fatigue and its investigation, Dr. P. B. Walker concerns himself with the structural aspects of aircraft fatigue, describing, incidentally, investigations carried out on large, and sometimes very large, specimens. That simultaneous action of corrosion and fatigue may lead to failure under stresses which normally would be borne without danger is well known, and Dr. R. B. Waterhouse discusses the theory and practice of corrosion fatigue, and the effect, sometimes large, of fretting. He concludes that "corrosion and fretting have a far greater influence on the fatigue strength than merely the production of pits in the surface which act as stress raisers", and again our ignorance rather than our knowledge of the phenomena involved appears to predominate.

Finally, Mr. P. H. Frith discusses the effect of temperature on fatigue properties over the range from liquid air temperatures to $870^{\circ} \mathrm{C}$. An enormous mass of material has been tabulated, and the engineerdesigner concerned with fatigue strength cannot but be grateful for the work involved.

Without pretending to be a comprehensive treatment of the subject, these lectures provide the engineer with a mass of detailed information, much of which is not readily accessible elsewhere in a condensed but easily assimilable form.

F. C. THOMpson

\section{ASTRONOMY AT THE CAPE OF GOOD HOPE}

\section{REPORT FOR 1955}

$\mathrm{T}$ HE Report of Her Majesty's Astronomer at the Cape of Good Hope to the Secretary of the Admiralty for $1955^{*}$ appears under seven headings, and in the first of these, "Buildings and Grounds", reforence is made to their fairly good general con. ditions at the time of the Report. As a result of the extensive programme of works and repairs carried out during the past fow years, relatively little maintenance had to be done in 1955. The work of ten instruments-including subsidiary equipment-is described under "Instruments"; the usual programme mentioned in previous Reports has been carried out, although the tower telescope was not used during 1955 owing to its ancient and rather unsteady mounting. This will receive a complete overhaul and the 6-in. lens will be repolished before the instrument is used again for serious work. The mirrors and tube for the 18-in. reflector were received from Messrs. Cox, Hargreaves and Thomson during 1955 and have been mounted on the equatorial stand built by Repsold in 1886 to carry the 7-in. heliometer. The reflector and the 7-in. Merz refractor have been mounted side by sido so that the refractor can be used either as a guiding telescope or independently for observing double stars. While the reflector is intended almost exclusively for photoelectric photometry, provision is being made for photography at the Cassegrain focus. Various other alterations have been made, including an almost entirely rebuilt stand, a new electric drive incorporating a Grubb type control and an independent

* Report of Her Majesty's Astronomer at the Cape of Good Hope to the Secretary of the Admiralty, for the year 1955. Pp. 10. (Royal Observatory, Cape of Good Hope, 1956.) two-speod electric slow-motion, transference of the main driving wheel from the top to the bottom of the polar axis, arrangemonts for setting directly in right ascension instead of in hour angle, and alterations to the shutter on the old heliometer dome.

"Observations and Reductions" deals with the usual work with the reversible transit circle, including observations for the "Second Cape Catalogue for 1950.0", begun in 1951. Some consideration has been given to the composition of the next catalogues to be observed with this instrument, and two interlinked programmes seem to be equally urgent. The first of these is the observation of the various groups of standard stars in as fundamental a way as possible; the second is the extension of the resulting fundamental system to a sufficient number of stars to ensure the adequate reduction of photographic observations. Datails of the scope of the schemes are given. Among the other usual subheadings reference may be made to Eros; measurement and reduction of forty-six plates of this minor planet which were taken during the 1954 opposition have been completed. About twelve reference stars per plate were used to reduce the effect of errors in their adopted proper motions, and a very interesting by-product of the investigation was the light it threw on the sizes of these errors. The proper motions from the Cape Astrographic Zone Catalogues, which were obtained by the differential measurement of two sets of photographic plates, are markedly superior, as regards relative accidental errors, to those in the more recent Cape and Yale Zone Catalogues which were obtained by comparing a photographic plate with an earlier meridian place.

Under "Meteorological Observations", reference is made to the Halliwell-Dines anemobiograph, in use since 1924, which had been giving considerable trouble through small leaks in the float. It was finally dismounted and replaced by the South African Meteorological Department with a Dines pressure-tube anemobiograph which was brought into use on August 12. Among other headings are "The Radeliffe Section", "The Time Service", "Publication of Results", "Personnel Establishment" and also "Miscellaneous", in which Dr. R. H. Stoy, H.M. Astronomer at the Cape, pays tribute to the work and enthusiasm of his staif.

\section{ICE-FORMING NUCLEI}

By DR. B. J. MASON and J. HALLETT

Imperial College of Science and Technology, London

TN an earlier communication ${ }^{1}$ we reported on the 1 ice-nucleating ability of a variety of chemical aerosols when introduced into a supercooled cloud formed in a diffusion and a large mixing-cloud chamber. Except in the case of silver iodide and lead iodide, these results were in disagreement with those of other workers in that we found many of the substances reported as highly effective ice-nuclei in the literature (notably silver nitrate, silver sulphate, the iodides of ammonia, potassium, sodium, cobalt, magnesium, manganese and thallium) to be quite inactive. Repeated tests with very pure chemicals in carefully cleaned air suggested that spurious results 